\title{
Building of information system frame for metrology testers
}

\author{
Jin-wei Qiao ${ }^{\mathrm{a},{ }^{*},}$ Xiao-hu Yin ${ }^{\mathrm{b}}$, Qing-guo Liang ${ }^{\mathrm{c}}$ \\ Unit 72465 of People's Liberation Army, Jinan, China, 250022 \\ ajoe613722@126.com, bphenixtiger@163.com, 'cshuangeli@163.com
}

Keywords: Metrology, Information system, Human resource.

Abstract. For the measurement work today, a wide range of equipment is running, the task itself is heavy, management mode is limited. In order to solve above problems this paper intends to build an information system for measurement testers. It has four modules, data input and maintenance, data statistics and analysis, data generation and system management. The information system was designed to combine human resources and equipment resources organically in metrology test system, making their management digitally. It played a positive role in major counterpart cultivation, human resource allocation, talent team construction and equipment resource maintenance and combination. The result of this paper propels the informatization of metrology test management.

\section{Introduction}

Measurement work is an important technical foundation work, playing an important role in world economic construction ${ }^{[1,2]}$. Compared to other industries, the meteorology industry in our country is relatively backward in management level .Modernization level of informatization is far behind the times, especially in human resource management. The job requires a lot of precision measurement equipment ${ }^{[3-5]}$. Many of them are powerful, special and always with a single supply channel. The operator needs individual training ${ }^{[6]}$. Post-maintenance services can only be obtained by contacting the manufacturer. The current situation, it is likely to cause the maintenance cycle too long to assure the progress of work. Worse more, without timely maintenance of equipment is likely to cause harm and affect measurement accuracy.

Also, each measuring and testing units need to cultivate their own metrology testers in order to maintain long-term normal work. With the development of social production informatization, meteorology personnel management informatization has become the development direction and focus. Metering personnel at all levels is a major component of personnel management. Change in personnel and temporary mobility of personnel will directly affect the operation of the entire unit of measurement, especially for the sudden emergency situation and emergency events. Person in charge of their staff at all levels need to have a comprehensive understanding of the situation and grasp. The more detailed division of labor is, the more dense contact is, the more statistical work needs to do, and the harder for human management is. The original artificial way was used to manage personnel affairs, which always leads to various errors for large amount of records. This article intends to build the platform that is to use software system to replace a lot of labor records. It can process lots of information conveniently and accurately. It can also be stored for a long time. Traditional artificial management of records on paper is not suitable for modern industrial development. To make personnel management realize systematization, standardization and automation will become the only access to industrial 4.0.

Meteorology and testing personnel information system is designed for operators and testers. It can improve the status of the current measurement test personnel management comprehensively, making it more standardized, more secure, easier and faster. Powerful statistical query functions provided by the system provide better support for decision making in the field of measurement data. 


\section{Construction goal}

In this paper, a structured development methodology was used to make requirement and system design for measure testers' management system. Firstly, business process diagrams and case diagram were applied to analyze and describe eight function process modules, including the personnel information management, the basic information management, the preparation of information management, the metering equipment information management, the personnel information statistics, the metering device information statistics, the data generation management and the system management in measuring and testing personnel management system. It also gives the conceptual design and logical design of the database.

\section{Platform function design}

The project selected the platform-independent J2EE architecture. Business logic is encapsulated into reusable components, and J2EE server provides the background services for all types of components in the form of the container. Because you do not need to make the development of this service by yourself, so you can focus on solving business problems at hand. Container and service container settings customized internal support provided by the J2EE server, Including security, transaction management, JNDI addressing, remote connectivity services. zThe following lists the most important of several services.

You can configure the web component or enterprise bean, so that only authorized users can access the system resources. Each customer belongs to a particular role, and each role is only allowed to activate specific method. Roles and activation methods can be stated in the enterprise bean arrangement description, and this declarative approach doesn't have to write the rules for strengthening the security.

When a client activates an enterprise bean method, the vessel gets involved in a management service. Due to container managed transactions, the enterprise bean is not necessary to encode affair border. Distributed Transaction codes that are required for control will be very complicated. It need a simple declaration of transaction attributes of enterprise bean in the arrangement described in the file, rather than writing or debugging complex code. The container will read this file and deal with this enterprise bean transactions. JNDI addressing services provides a unified interface to multiple enterprise name and directory services, so application components can access the names and directory services ${ }^{[7]}$.

The management client has interaction with the enterprise bean's lower layer. When an enterprise bean is created, the way a client calls it is just like they are on the same virtual machine. In order to create and remove management enterprise bean, an enterprise bean in their life cycle will experience several states. Container creates enterprise bean, moves it in the available pool of instances and the active state, and eventually removes it from the container. Even if you can call creating and removing enterprise bean's method, the container will also perform these tasks in the background. Enterprise bean can quickly obtain a connection from the pool. It may be used for other bean after releasing from the connection. 


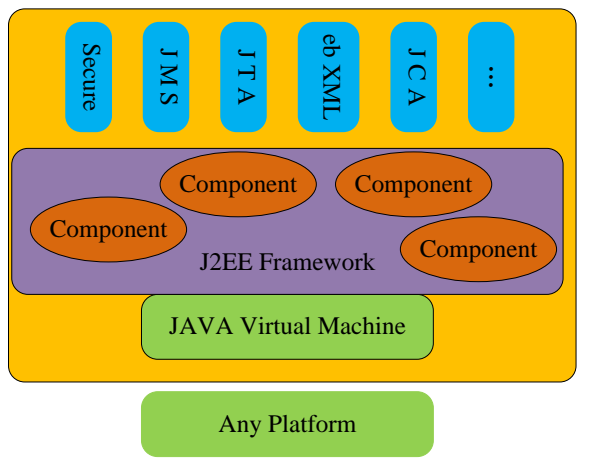

Figure 1 J2EE Technology Structure

\section{Function Module Description}

As shown in Fig. 2, the measurement and testing personnel information system is composed of eight functions which are personnel information maintenance, basic information maintenance, training information, equipment information, personnel information statistics, device information statistics, data generation and system administration.

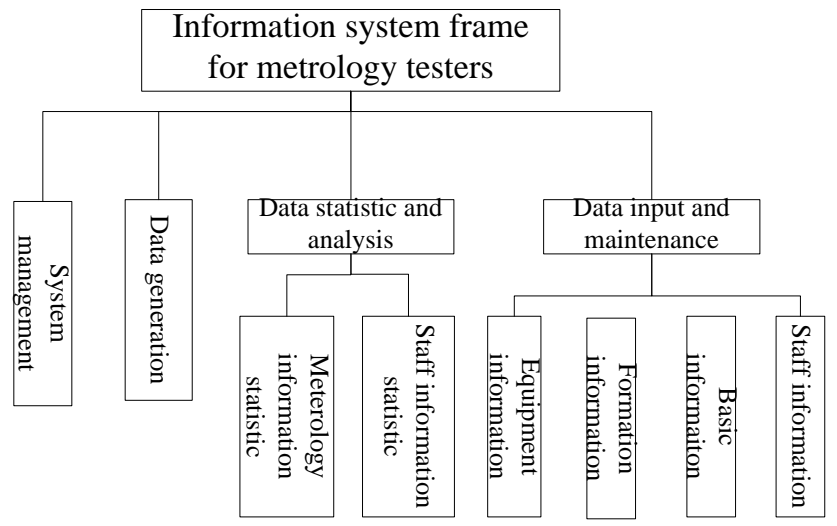

Figure 2 Platform overall functional construction graph

Personnel information maintenance consists of two parts, cadre information maintenance and employee information maintenance. Each function can query, add, modify and delete the data. It can adjust the organization for Personnel changes at any time, and simple and fast change is possible for late personnel changes.

Basic information maintenance includes eight functional components. They are graduate school information, major event information, cadres level information, cadres title information, cadres technology level information, cadres professional information and employee contract information. Each function can query, add, modify and delete the data. It can be simple and convenient to operate basic information. Training information includes two functional components, cadre training information and staff training information. Each function can query, add, modify and delete the data. Device information is mainly to query, add, modify and delete training situations data from new equipment. Personnel information statistics includes cadre training statistics, staff training statistics, existing cadre statistics, existing staff statistics. This function can make statistics following different angles, or from multi-dimensions. It can generate data lists, pie charts, bar charts, line charts, mixed graph. It also can directly observe real-time changes in data. Device information statistics includes statistics by device category and by affiliation. This function can be performed statistics in accordance with the device 
affiliation and equipment category. It can generate data lists, pie charts, bar charts, line charts, mixed graph. It also can directly observe real-time changes in data.

Data generation includes local data backup, local data recovery, update data import, reported data generation and issued data generating. The main function is to offer data generated in the process with disastrous protection and utilization. Real-time field data can have seamless connection with other measurement units. System management includes organization management, role management, functional module management, system log function. Organizational management is mainly responsible for distribution and organization between superior and the subordinate levels. The role management focuses on user access control. Function module management is a system initialization function. Operation log records staff operation log, system operation and system exception log.

\section{Information input method}

The main function of data entry and maintenance is to collect and aggregate the preparation of measurement tester, cadre basic information, employee basic information, step by step. It can provide measured or regulatory agencies at all levels with data to have a better understand of the situation of metrologists.

Personnel range is the management and metrology personnel directly related to the measurement test and measurement equipment.

Basic information maintenance mainly includes four aspects, Measurement staffing management, basic information management, training management and rewards \& punishments management, as shown in Fig. 3.

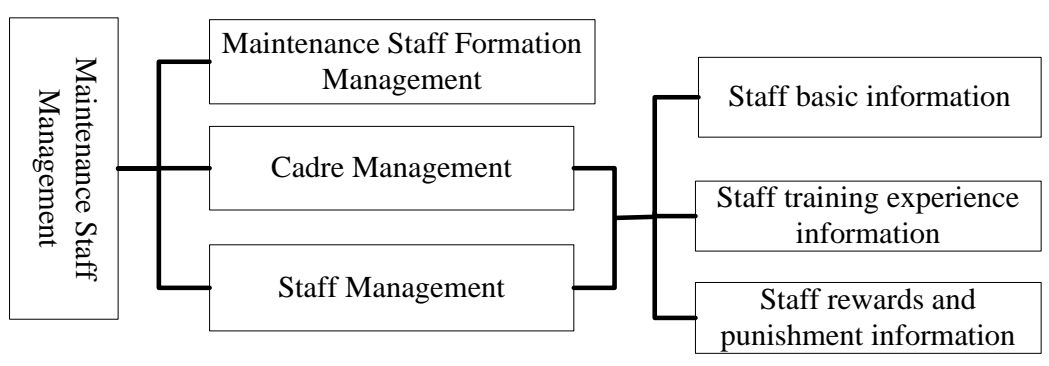

Fig. 3 measurement personnel management structural diagram

1) Measurement staffing formation management

Formation management of measurement personnel is mainly used for recording formation of concerned measurement staffing in each measurement unit.

2) Staff basic information

Measurement and Testing engaged staff, including cadres and employees can have their basic information logged based on their ID number. The basic information includes name, age, hometown, entry time, post level and so on.

3 ) Staff profession training experience information management

It mainly records training status of cadres and staff, figuring out the knowledge structure for every staff.

4) Staff reward and punishment information management

Personal reward and punishment can be recorded here to express everyone's different work ability.

For different professional layout and design staff allocation, statistical analysis was made through different angles. Fig. 4 gives main content. 


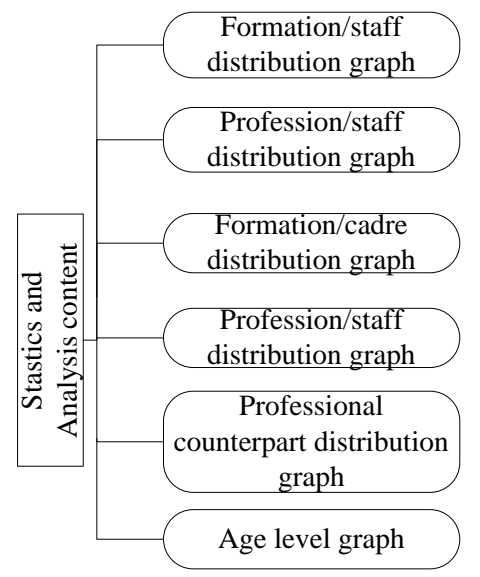

Figure 4 Content of statistic and analysis

The basic flow of personnel management is order flow, as shown in Fig. 5. Firstly, the formation was logged and maintained. Then log and maintain the staff basic information. After that, training information was treated according to different training situation. The newest staff status was at last gained that includes all subordinate units. Escalate step by step, and summary step by step.

\begin{tabular}{|c|c|c|c|c|c|}
\hline $\begin{array}{l}\text { Maintenance } \\
\text { staff formation } \\
\text { Registry } \\
\end{array}$ & $\rightarrow \begin{array}{c}\text { Maintenance staff } \\
\text { basic information } \\
\text { Registry }\end{array}$ & $\rightarrow \begin{array}{c}\text { Maintenance staff } \\
\text { training experience } \\
\text { Registry }\end{array}$ & $\begin{array}{c}\text { Maintenance staff } \\
\text { reward and } \\
\text { punishment Registry }\end{array}$ & $\begin{array}{c}\text { Statistic and } \\
\text { query }\end{array}$ & Report \\
\hline
\end{tabular}

Fig. 5 Basic flow of personnel information management

In the specific implementation process, entry of staffing formation information and basic information are shown in Figs. 6 and 7, respectively.

\section{Conclusion}

Based on the stated goal of building, this paper makes a platform functional design, describe various functional modules. The built information system includes four modules, i.e. data entry and maintenance, data analysis, data generation and system management. On this basis, staffing formation information maintenance and staff basic information are given as two examples to give out specific method for information entry. The building of the information system provides reference for information technology in the field of metrology.

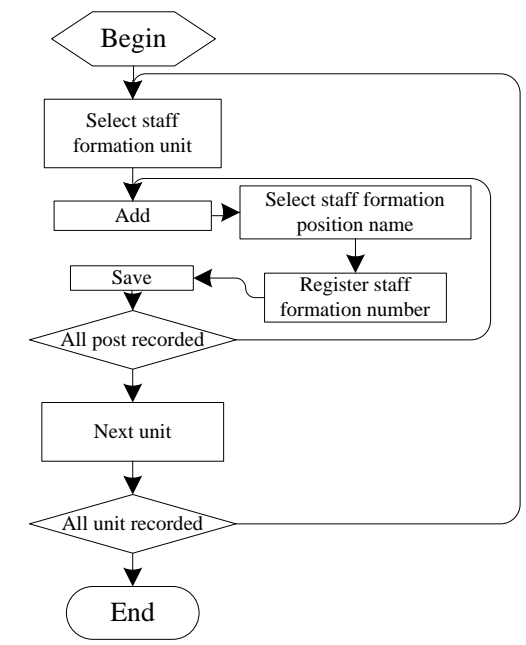

Figure 6 Staff formation maintenance 


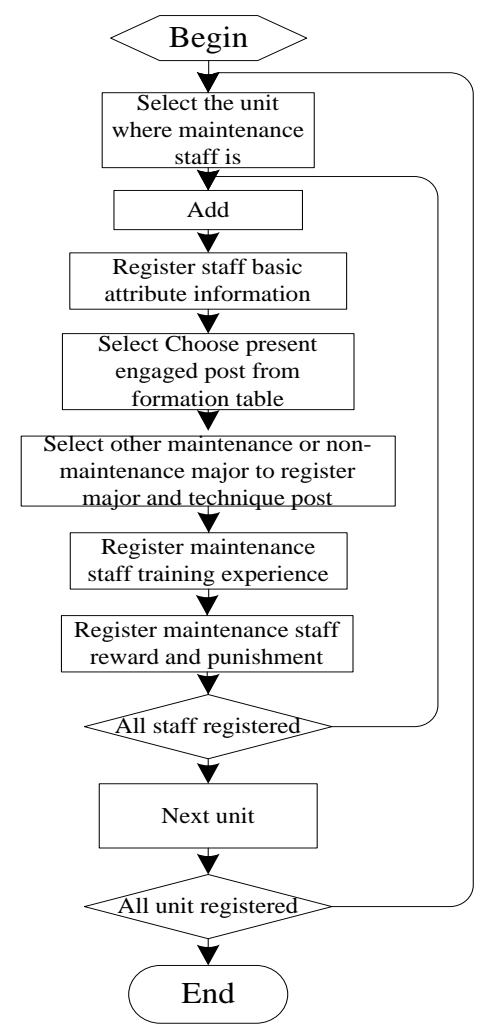

Figure 7 Staff basic information input

\section{References}

[1] Strotz L C. Spatial patterns and diversity of foraminifera from an intermittently closed and open lagoon, Smiths Lake, Australia[J]. Estuarine, Coastal and Shelf Science. 2015, 164: 340-352.

[2] Anderson D J, Kobryn H T, Norman B M, et al. Spatial and temporal patterns of nature-based tourism interactions with whale sharks (Rhincodon typus) at Ningaloo Reef, Western Australia[J]. Estuarine, Coastal and Shelf Science. 2014, 148: 109-119.

[3] Ni C, Bell R W, Mcgrath W, et al. Role of soil covers in establishment of vegetation on gold oxide refining residues[J]. Ecological Engineering. 2015, 75: 392-403.

[4] Salih T, Wang Y, Adam M A A. Renewable Micro Hybrid System of Solar Panel and Wind Turbine for Telecommunication Equipment in Remote Areas in Sudan[J]. Energy Procedia. 2014, 61: 80-83.

[5] Sundén E, Kottravel S, Ropinski T. Multimodal volume illumination[J]. Computers \& Graphics. 2015, 50: 47-60.

[6] Liang C, Jaksa M B, Ostendorf B, et al. Influence of river level fluctuations and climate on riverbank stability[J]. Computers and Geotechnics. 2015, 63: 83-98.

[7] Carolan-Olah M, Frankowska D. High environmental temperature and preterm birth: A review of the evidence[J]. Midwifery. 2014, 30(1): 50-59. 